\title{
Molecular Phylogenetic Study on Pseudomonas stutzeri Isolated from Currency Notes in Khartoum State, Sudan and Identified Via16s rRNA Gene Sequence Analysis
}

\author{
Mosab Yahya Al-Nour, ", Malik Suliman Mohamed², Noha Ahmed Abd Alfadil ${ }^{3}$, \\ Hisham Nouraldayem Altayb ${ }^{4}$, Salah-Eldin Gumaa El-lzaki ${ }^{5}$, Mohamed Ahmed Hassan ${ }^{6}$ \\ ${ }^{1}$ Department of Pharmaceutical Chemistry, Faculty of Pharmacy, Omdurman Islamic University, Khartoum, Sudan \\ ${ }^{2}$ Department of Pharmaceutics, Faculty of Pharmacy, University of Khartoum, Khartoum, Sudan \\ ${ }^{3}$ Department of Pharmaceutical Microbiology, Faculty of Pharmacy, University of Alneelain, Khartoum, Sudan \\ ${ }^{4}$ Department of Microbiology, College of Medical Laboratory Science, Sudan University of Science and Technology, Khartoum, Sudan \\ ${ }^{5}$ Department of Epidemiology, Molecular Epidemiology Laboratory, Tropical Medicine Institute Research, Khartoum, Sudan \\ ${ }^{6}$ Applied Bioinformatics Center, Africa City of Technology, Khartoum, Sudan
}

Email address:

mosabyahiaalnour@gmail.com (M. Y. Al-Nour)

${ }^{*}$ Corresponding author

To cite this article:

Mosab Yahya Al-Nour, Malik Suliman Mohamed, Noha Ahmed Abd Alfadil, Hisham Nouraldayem Altayb, Salah-Eldin Gumaa El-lzaki, Mohamed Ahmed Hassan. Molecular Phylogenetic Study on Pseudomonas stutzeri Isolated from Currency Notes in Khartoum State, Sudan and Identified Via16s rRNA Gene Sequence Analysis. European Journal of Biophysics. Vol. 5, No. 6, 2017, pp. 104-111.

doi: $10.11648 /$ j.ejb.20170506.12

Received: November 28, 2017; Accepted: December 19, 2017; Published: January 17, 2018

\begin{abstract}
Pseudomonas stutzeri is a valuable bacteria for understanding of the taxonomical and the phylogenetic relationships. The study of genetic relationships between organisms or genes is carried out by molecular phylogeny. We aim to study the relationships according to $16 \mathrm{~S}$ rRNA gene sequences between our samples and the closest strains from other countries over the world. To our knowledge, the phylogenetic studies between strains from Sudan with strains from other countries were not done before. A total of 140 currency notes in different denominations were collected randomly from several locations including hospitals, food sellers and transporters. From the collected notes, a total of 135 bacterial colonies were isolated and from them 14 isolates were identified as a pseudomonas stutzeri. In the study, streaking plate method was used for the isolation of pure bacterial culture, Chelex 100 method was used for DNA extraction, conventional PCR was used for amplification of the targeted gene, agarose gel electrophoresis and various bioinformatics tools were used for nucleotide sequence analysis. The PCR products were sent for Macrogen Company-Netherlands for purification and nucleotide sequencing. After sequencing 3 samples were noisy, hence they were excluded. According to phylogenetic analysis, we found that the samples were closely related to strains from south-east Asia (Indonesia), east Asia (China), south-central Asia (Bangladesh), south Asia (India), north Africa (Tunisia) and south Europe (Italy and Greece). Despite the samples were from the same source (currency notes), we found that there is broad sequence variation between them.
\end{abstract}

Keywords: Pseudomonas stutzeri, Currency Notes, Molecular Phylogenetic, Khartoum, Sudan

\section{Introduction}

Pseudomonas stutzeri is a gram negative straight rod [5] belonging to gamma-Proteobacteria [6].

Strains of $P$. stutzeri exhibit broad genotypic diversity [7], [8] consequently, P. stutzeri is a valuable bacteria for understanding of the taxonomical and the phylogenetic relationships [9].

The study of genetic relationships between organisms or genes is carried out by molecular phylogeny via the 
comparing of protein or homologous DNA sequences such as ribosomal RNA and mitochondrial genes. Ribosomal RNA consists of highly conserved and variable regions as well as it is universal, consequently, is a valuable target for the phylogenetic studies [10].

P. stutzeri strains are characterized by their ability to grow in broad range of temperature, anaerobically, and organotrophically (via utilization of many organic substrates) as well as the resistance to heavy metals. Therefore, they were isolated from various environments including soil, groundwater, rhizosphere marine water, sediment, wastewater [5], clinical materials [11] and currency notes [12]. Many studies on the genotypic identification and phylogenetic analysis of $P$. stutzeri were performed via several highly specific and sensitive molecular markers including 16S rRNA gene [5]. In Sudan, it was isolated and identified via conventional methods [13], [14], [15] as well as $16 \mathrm{~S}$ rRNA gene [16].

After the Isolation and Identification of bacteria, we aim to study the relationships according to $16 \mathrm{~S}$ rRNA gene sequences between our samples and the closest strains from other countries over the world. Within the Ribosomal RNA genes, 16S rDNA is the most universal and conservative, therefore it is the most valuable in phylogenetic [17], hence it was selected for the study. To our knowledge, the phylogenetic studies between strains from Sudan with strains from other countries were not done before.

\section{Materials and Methods}

This study was conducted in Faculty of pharmacy, Omdurman Islamic University in collaboration with the Applied Bioinformatics Center, Africa City of Technology and the Department of Epidemiology, Tropical Medicine Research Institute, National Center for Research, Khartoum, Sudan between May 2016 and July 2016. A total of 140 currency notes in 5, 10, 20 and 50 denominations were collected randomly from different locations including hospitals, food sellers and transporters. The collected notes were placed into sterile plastic petri dishes and transferred to the laboratory.

\subsection{Microbiological Methods}

Firstly, the collected currency notes were moistened with sterile distilled water and swabbed at both sides cotton tipped swabs. The swabs were directly inoculated in 5\% blood agar plates, incubated aerobically for 24 hours at $37^{\circ} \mathrm{C}$, sub cultured in MacConkey and Cetrimide agars and incubated for 24 hours at $37^{\circ} \mathrm{C}$. After that, the single colonies were isolated, cultured into nutrient agar plates and identified phenotypically (gram staining and biochemical tests) according to protocols described in Monica Cheesbrough [18]. Several biochemical tests were performed including Oxidase, Catalase, Indole, Glucose and Lactose fermentation, Citrate, Urease and Motility tests. The results of biochemical tests are listed in Table 2. A total of 135 bacterial colonies were isolated and from them 21 isolates were identified as a pseudomonas species.

\subsection{Molecular Methods}

At first, streaking plate method was used for the isolation of pure bacterial culture [19]. Next, $200 \mu 1$ from $1 \mathrm{X}$ phosphate buffer saline were taken and transferred to sterile $1.5 \mathrm{ml}$ eppendorf tube by micropipette. Then, the distinctive colonies from the pure bacterial culture were isolated and inoculated into the eppendorf tubes. After that, Chelex 100 method was used for DNA extraction [20], conventional PCR was carried out via Alpha Unit Block Assembly DNA Thermo cycler from Bio-RAD Company by using Maxime PCR premix kit (i-Taq, for 20 $\mu 1$ reaction) from INtRON Biotechnology with the universal primers $27 \mathrm{~F}$ and $1495 \mathrm{R}$ that have the sequences (5'-AGAGTTTGGATCMTGGCTCAG-3) and (5'CTACGGCTACCTTGTTACGA-3') respectively [21].

The PCR reaction volumes are listed below in Table 3 and temperature cycles involved initial denaturation cycle at $94^{\circ} \mathrm{C}$ for 5 minutes, followed by 35 amplification cycles ( 1 minute at $94^{\circ} \mathrm{C}, 1$ minute at $58^{\circ} \mathrm{C}$ and 2 minute at $72^{\circ} \mathrm{C}$ ) as well as final extension cycles at $72^{\circ} \mathrm{C}$ for 10 minutes [21]. After that, agarose gel electrophoresis was carried out against the obtained PCR amplicons via Amersham gel electrophoresis device according to protocol described by Lee. P. Y et al. [22] and the PCR products wre sent to Macrogen Company-Netherlands for purification and nucleotide sequencing of both strands.

\subsection{Bioinformatics Analysis}

After obtaining the sequences, firstly they were checked and corrected them manually via Finch TV software [23]. From the received sequences, 14 sequences were identified as $P$. stutzeri via nucleotide BLAST tool at NCBI [24], but 3 sequences of them were noisy, consequently they were excluded. After that, various bioinformatics tools were used including GenBank database [25] to obtain the sequences of previously identified genomovars and strains with higher identity.

In addition to that, Clustal $\mathrm{W}$ algorithm was used for multiple sequence alignment [26] and BioEdit software [1] for the visualization of multiple sequence alignment. Moreover, MEGA 6.06 [4] was used for phylogenetic analysis and Unipro UGENE software [27] was used for the calculation of simple identity in percent. The closest strains (sequences with higher identity in BLAST search) that we used for phylogenetic analysis with their accession numbers are listed table 1.

Nucleotide Sequence Accession Numbers

The identified nucleotide sequences were deposited in the GenBank database [25] under the accession numbers KY039354 to KY039364 that listed in Table 4. 
Table 1. Nucleotide sequences of stains with higher identity in BLAST search [19] obtained from GenBank database [20].

\begin{tabular}{|c|c|c|}
\hline Strain & Country & Accession number \\
\hline VKM B-97 & USA & NR_116489.1 \\
\hline 0511MAR14N1 & Spain & LN7̄774555.1 \\
\hline APB6 & China & KP768391.1 \\
\hline 1005 & India & KU749990.1 \\
\hline SL-02 & Indonesia & KX082892.1 \\
\hline SC-04 & Indonesia & KX082841.1 \\
\hline SP-09 & Indonesia & KX082842.1 \\
\hline SR-23 & Indonesia & KX082843.1 \\
\hline TRA27A & Spain & JQ782508.1 \\
\hline K-2-7 & Iran & JQ963329.1 \\
\hline F1 & China & HQ292192.1 \\
\hline A10 & Tunisia & KU180229.1 \\
\hline EGY-SCM1 & Egypt & KJ545584.1 \\
\hline OOYW-9 & Italy & KJ534280.1 \\
\hline ME-1 & Pakistan & KF975434.1 \\
\hline A160/74 & Spain & HF571089.1 \\
\hline MH004 & Egypt & KU855015.1 \\
\hline Gr45 & Greece & FR667889.1 \\
\hline Gr17 & Greece & FN813477.1 \\
\hline B11 & China & KT380516.1 \\
\hline W45 & China & KT380587.1 \\
\hline BD-2.2.1 & Vietnam & LC125170.1 \\
\hline B15 & China & KT380520.1 \\
\hline MN1 & India & KU708859.1 \\
\hline NA3 & India & KU708861.1 \\
\hline Bon_a1 & United Kingdom & FN397901.1 \\
\hline $\mathrm{Xmb} 018$ & China & KT986148.1 \\
\hline KG-2 NRB-DRDO MP & India & KX344913.1 \\
\hline NB-03 & Pakistan & KX262874.1 \\
\hline SP-10 & Indonesia & KX082893.1 \\
\hline 40/D/Mac2 & Bangladesh & KT716345.1 \\
\hline $\mathrm{Bd} 8$ & Sudan & KJ801394.1 \\
\hline N55 & China & KJ004621.1 \\
\hline I-A-E-25 & Poland & KT922026.1 \\
\hline ARO3 & Brazil & KP744123.1 \\
\hline W12 & China & КT380558.1 \\
\hline W1 & China & KT380544.1 \\
\hline
\end{tabular}

\section{Results and Discussion}

The nucleotide sequence chromatogram, nucleotide BLAST search results, multiple sequence alignment of samples with strains of higher identity obtained from GenBank database [25] are shown in Figure 1,2 and 3 respectively.

$P$. stutzeri strains have almost a universal environmental distribution [5], hence it is not strange to be isolated from currency notes. In the same manner, Kalita $\mathrm{M}$ et al. isolated $P$. stutzeri from currency notes [12].

After isolation, identification of bacteria and the phylogenetic analysis, we found that sample 1 clustered with strain SC-04 from Indonesia in the same phylogenetic sub branch $(100 \%$ sequence identity), sample 2 was closely related to strain N55 from China (100\% sequence identity) and Bd8 from Sudan (99\% sequence identity). Also, sample 3 clustered with strain OOYW-9 from Italy ( $95 \%$ sequence identity) and sample 4 was closely related to strain SR-23 (100\% sequence identity) from Indonesia and Gr45 from Greece ( $100 \%$ sequence identity). In addition, sample 5 was closely related to strain PIGB61 from India (100\% sequence identity) and 40/D/Mac2 from Bangladesh (100\% sequence identity), sample 6, 7, 11 was closely related to strain APB6 from China (100\% sequence identity) and sample 8, 9, 10 was closely related to strain CB44 from China and A10 from Tunisia (99-100\% sequence identity) (Figure 5 and 6 ).

In contrast, we found that other strains from China (B11, W1, W12, and W45) are closely related to other strains from Egypt (MH004 and EGY-SCM1), Iran (K-2-7), Poland (I-A-E-25), Brazil (ARO3), Indonesia (SP-10) and Greece (Gr17). Moreover, other strains from India (NB-03, NA3, KG-2 NRBDRDO MP and 1005) are closely related to other strains from Pakistan (ME-1 and NB-03), Bangladesh (40/D/Mac2) and Spain (A160/74) (Figure 5). This finding reflects the geographical variation in habitats of $P$. stutzeri strains as the samples were closely related to strains from south-east Asia (Indonesia), east Asia (China), south-central Asia (Bangladesh), south Asia (India), north Africa (Tunisia) and south Europe (Italy and Greece[28]. Unfortunately, currency notes are widely circulating agents making the identification of the exact location from which our samples were isolated is difficult. 


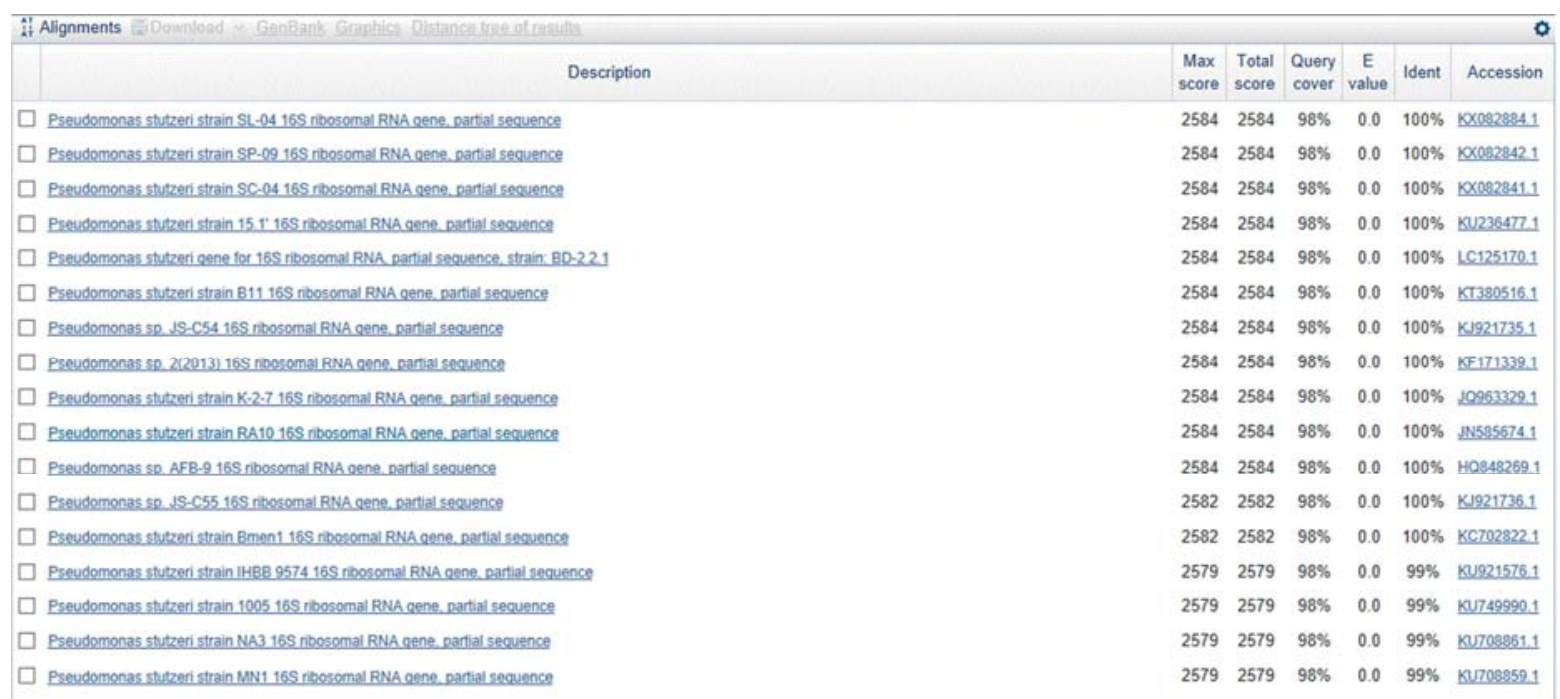

Figure 1. Nucleotide sequence chromatogram.

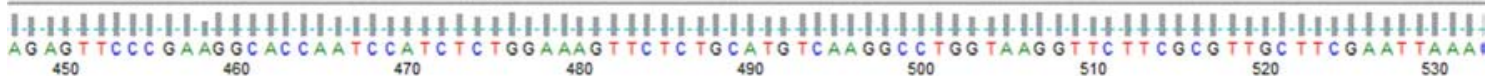

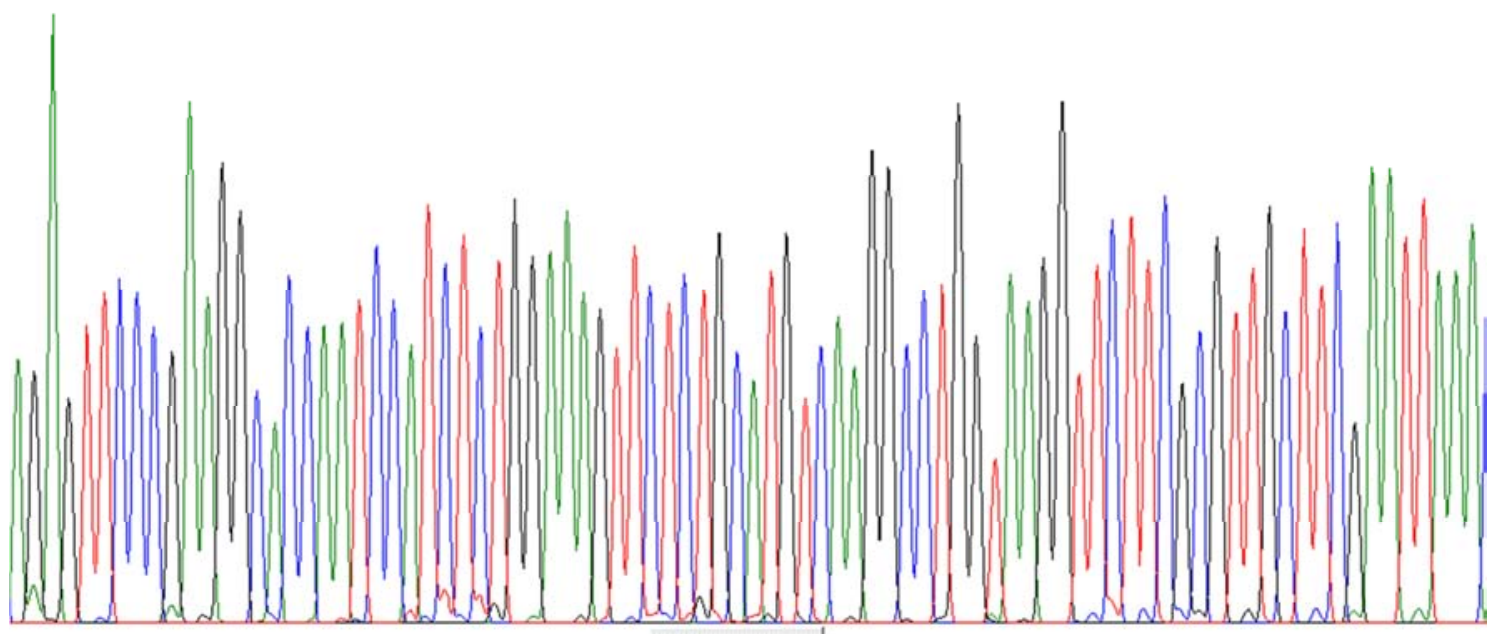

Figure 2. Nucleotide BLAST [20] search Results.

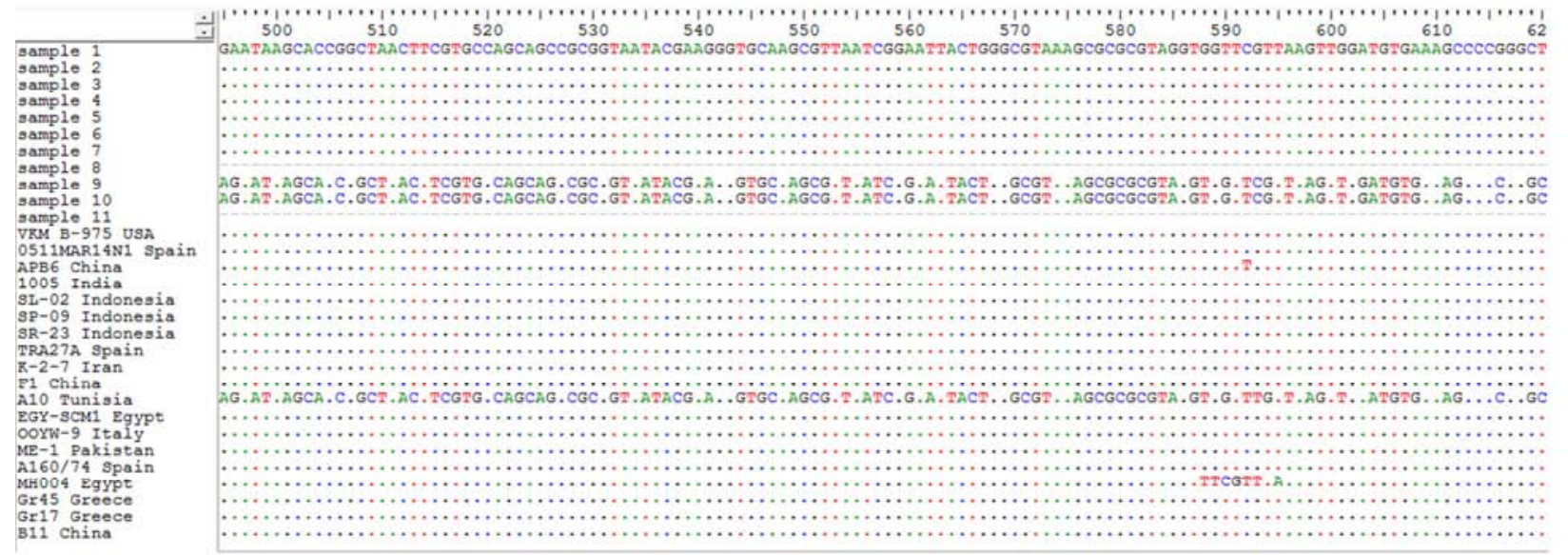

Figure 3. Multiple Sequence Alignment of samples with strains of higher identity obtained from GenBank database [20] carried out via Clustal W multiple alignment algorithm [21] on MEGA 6.06 [22] and visualized via BioEdit software [1]. 


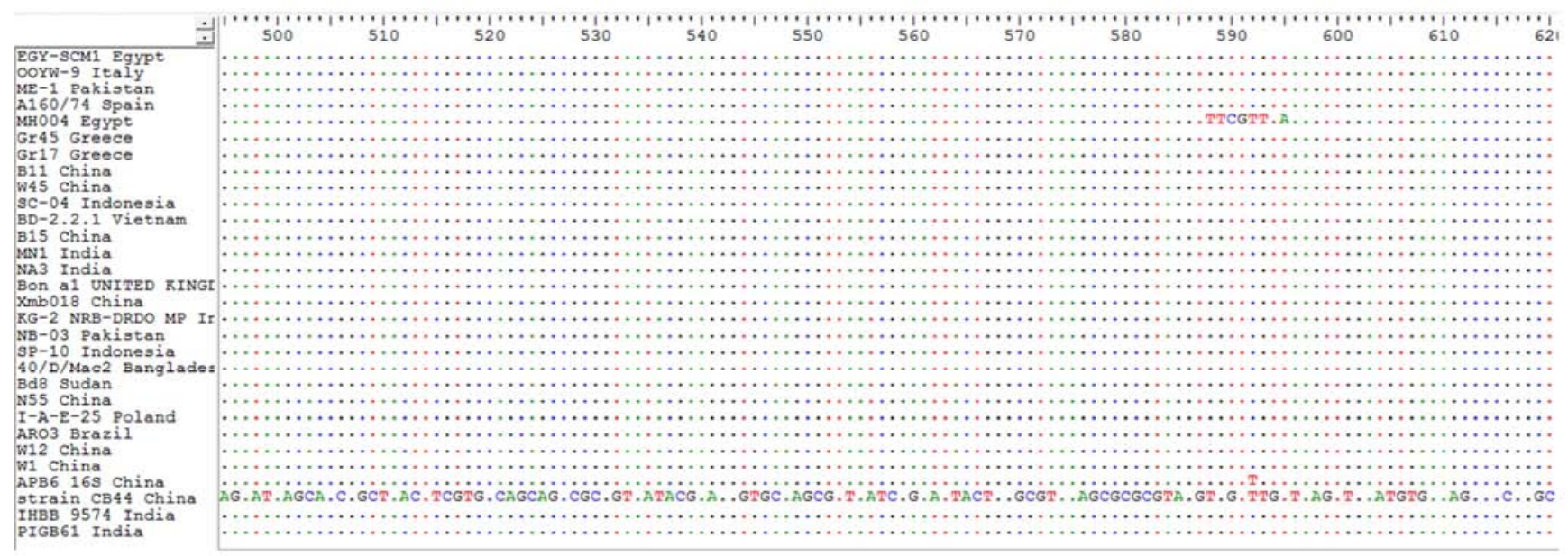

Figure 4. Multiple Sequence Alignment of samples with strains of higher identity obtained from GenBank database [20] carried out via Clustal $W$ multiple alignment algorithm [21] on MEGA 6.06 [22] and visualized via BioEdit software [1].

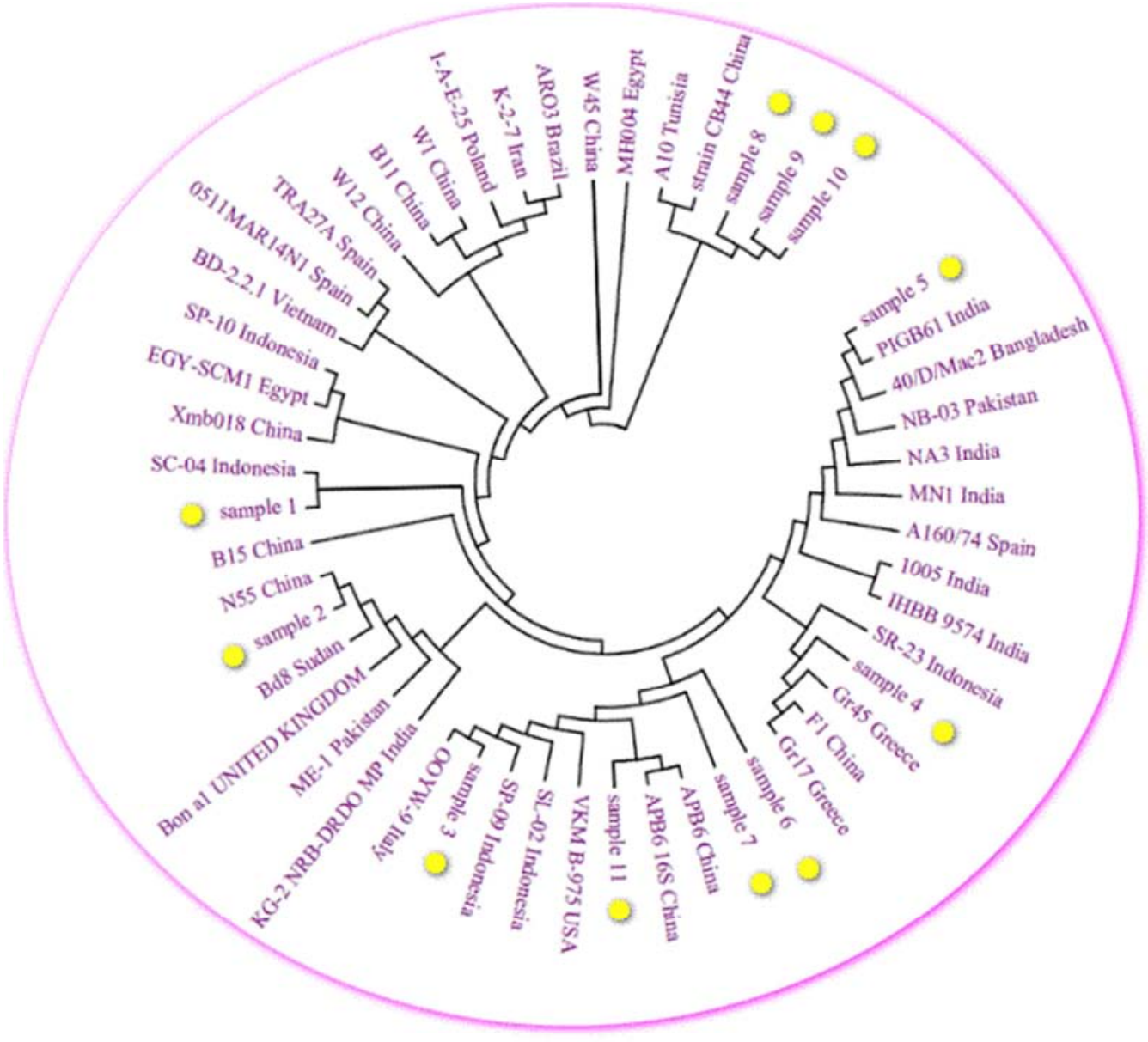

Indicates the positions of our samples

Figure 5. Molecular Phylogenetic Analysis on samples and strains with higher identity via 16S rRNA gene sequences.

The evolutionary history was inferred via the Maximum Likelihood method based on the Jukes-Cantor model [2]. The bootstrap consensus tree inferred from 2000 replicates [3] was taken to represent the evolutionary history of the analyzed samples [3]. Branches corresponding to partitions reproduced in less than $50 \%$ bootstrap replicates were collapsed. Initial tree for the heuristic search was achieved by applying the Neighbor-Joining method to a matrix of pairwise distances estimated via the Maximum Composite Likelihood (MCL) approach. The analysis involved 52 nucleotide sequences. There were a total of 
1519 positions in the final dataset. The evolutionary analyses were conducted in MEGA6 [4].
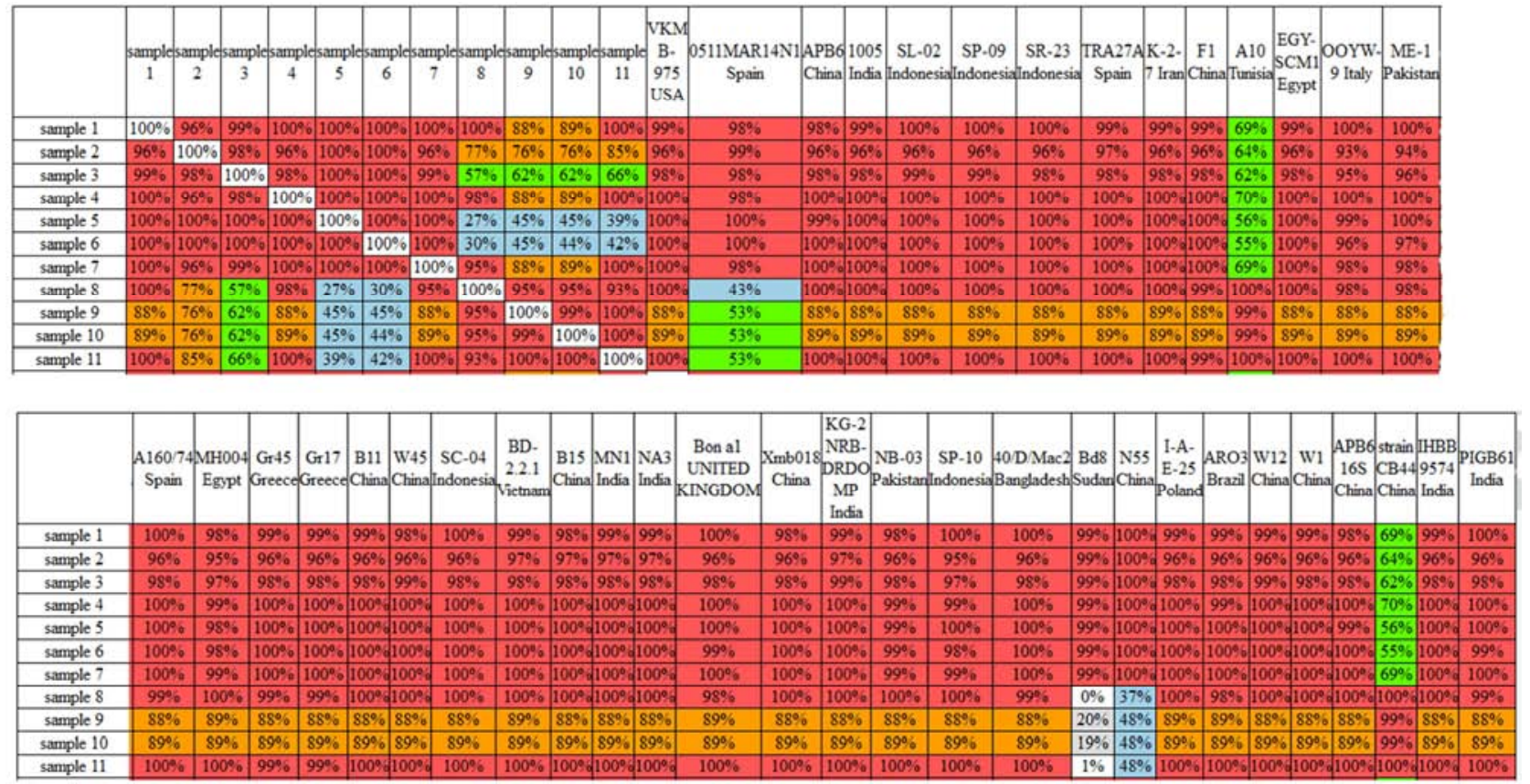

Figure 6. Simple Identity in $16 \mathrm{~S}$ rRNA gene between samples and strains with higher identity after they were aligned via Clustal $W$ multiple alignment algorithm [3] on MEGA 6.06 [4].

Despite the samples from the same source (currency notes), according to the results of multiple sequence alignment results (Figure 3 and 4), we found that there is a broad sequence variation between them in the nucleotide positions 495-620. In these positions, sample 1, 2, 3, 4, 5, 6 and 7 are identical (group A) as well as sample 9 and are identical (group B) with strain A10 from Tunisia and CB44 from China. In contrast, the sequences of sample 8 and 11 were not involving these nucleotide positions because they were partial sequences; hence they were represented by dashes.

The genotypic variation between $P$. stutzeri strains can be interpreted by the natural transformation [29] and rearrangements in their genomic organization (not conserved) [30] that predominantly may be as a result of adaptation to specific environment [31]. In this respect, Sikorski et al. [32] found that the transformability is common among environmental $P$. stutzeri strains.

As the Strains of $P$. stutzeri exhibit broad genotypic diversity, they were sub classified into DNA-DNA similarity groups termed as genomovars [7], [8]. In order to predict the genomovars that the samples belong, we carried out phylogenetic analysis between our samples and other strains from previously identified genomovars. We found that our samples were closely related to strains from genomovar 1 and 5 (Figure 7), but in order to confirm this result, further identification with other housekeeping genes beside $16 \mathrm{~S}$ rDNA must be carried out.

In fact, currency notes from several countries over the world were found to be contaminated with many resistant microorganisms. The isolation of bacteria from currency notes is alarm that needs attention and health education especially in the development countries in order to prevent the risks and health hazards facing individuals be in contact with contaminated currency notes [33].

16S rDNA is characterized by its slow rate of evolution, consequently it have been used broadly for the phylogenetic reconstruction [34]. We found that 16S rDNA sequence analysis is a valuable method for the study, because it provides considerable results that achieved the objective.

The sample size was small and other genes beside the $16 \mathrm{~S}$ rRNA gene were not used in the study, consequently the authors recommend the avoiding of these limitations for better identification and phylogenetic analysis.

\section{Conclusion}

P. stutzeri was identified in currency notes via $16 \mathrm{~S}$ rDNA sequence analysis. According to the phylogenetic analysis, we found that the samples are closely related to strains from Indonesia (SC-04 and SR-23), China (N55, CB44 and APB6), Bangladesh (PIGB61), India (40/D/Mac2), Tunisia (A10), Greece (Gr45), Italy (OOYW-9) and other strain from Sudan (Bd8).

\section{Conflict of Interest}

The Authors declare that they have no conflict of interest. 


\section{Appendix}

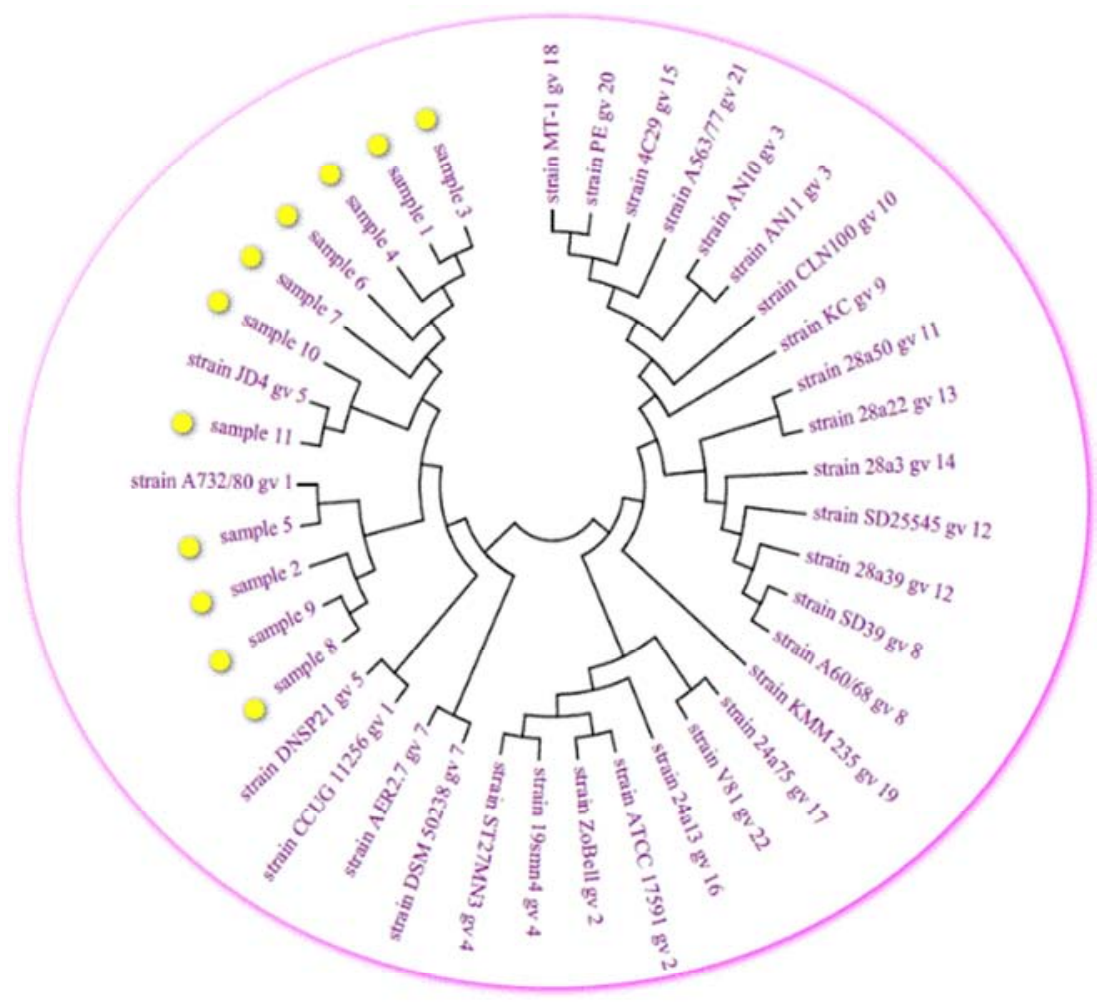

Indicates the positions of our samples.

Figure 7. Molecular Phylogenetic analysis on our samples and strains from various genomovars via $16 S$ rDNA sequences.

The evolutionary history was inferred via the Maximum Likelihood method based on the Jukes-Cantor model [2]. The bootstrap consensus tree inferred from 2000 replicates [3] was taken to represent the evolutionary history of the analyzed samples [3]. Branches corresponding to partitions reproduced in less than $50 \%$ bootstrap replicates were collapsed. Initial tree for the heuristic search was achieved by applying the Neighbor-Joining method to a matrix of pairwise distances estimated via the Maximum Composite Likelihood (MCL) approach. The analysis involved 40 nucleotide sequences. There were a total of 1516 positions in the final dataset. The evolutionary analysis was conducted in MEGA6 [4].

gv. is an abbreviation for genomovar.

Table 2. Results of the Biochemical Tests.

\begin{tabular}{ll}
\hline Biochemical test & result \\
\hline Oxidase & positive \\
Catalase & positive \\
Indole & negative \\
Glucose fermentation & positive \\
Lactose fermentation & positive \\
Citrate & positive \\
Urease & negative \\
Motility & positive \\
\hline
\end{tabular}

Table 3. PCR reaction volumes according to INtRON Biotechnology company instructions.

\begin{tabular}{ll}
\hline PCR reaction mixture & Volume $(\boldsymbol{\mu l})$ \\
\hline DNA extract & 5 \\
Forward Primer $(10 \mathrm{pmol} / \mu \mathrm{l})$ & 1 \\
Reverse Primer $(10 \mathrm{pmol} / \mu \mathrm{l})$ & 1 \\
Distilled water & 13 \\
Maxime PCR preMix $(20 \mu \mathrm{l}$ reaction $)$ & 5 \\
Total volume & 25 \\
\hline
\end{tabular}

Table 4. Accession numbers of our samples.

\begin{tabular}{lll}
\hline Sample number & location & Accession number \\
\hline 1 & transporters & KY039354 \\
2 & Khartoum Teaching Hospital & KY039355 \\
3 & Khartoum Teaching Hospital & KY039356 \\
4 & food sellers & KY039357 \\
5 & food sellers & KY039358 \\
6 & food sellers & KY039359 \\
7 & transporters & KY039360 \\
8 & food sellers & KY039361 \\
9 & transporters & KY03939363 \\
10 & Omdurman Teaching Hospital & KY039364 \\
11 & Omdurman Teaching Hospital & \\
\hline
\end{tabular}

\section{References}

[1] Bio Edit software. (http://www.mbio.ncsu.edu/bioedit/bioedit.html). 
[2] Jukes TH, Cantor CR (1969) Evolution of protein molecules. Mammalian protein metabolism 3: 132.

[3] Felsenstein J (1985) Confidence limits on phylogenies: an approach using the bootstrap. Evolution: 783-791.

[4] Tamura K, Stecher G, Peterson D, Filipski A, Kumar S (2013) MEGA6: molecular evolutionary genetics analysis version 6.06. Molecular biology and evolution 30: 2725-2729.

[5] Lalucat J, Bennasar A, Bosch R, Garcia-Valdes E, Palleroni NJ (2006) Biology of Pseudomonas stutzeri. Microbiol Mol Biol Rev 70: 510-547. doi: 10.1128/MMBR.00047-05.

[6] Stackebrandt E, Murray RGE, Trüper HG (1988) Proteobacteria classis nov., a Name for the Phylogenetic Taxon That Includes the "Purple Bacteria and Their Relatives". International Journal of Systematic and Evolutionary Microbiology 38: 321-325. doi:10.1099/00207713-38-3-321.

[7] Rosselló - Mora R, Lalucat J, Dott W, Kämpfer P (1994) Biochemical and chemotaxonomic characterization of Pseudomonas stutzeri genomovars. Journal of applied bacteriology $76: 226-233$.

[8] Rosselló R, García-Valdés E, Lalucat J, Ursing J (1991) Genotypic and phenotypic diversity of Pseudomonas stutzeri. Systematic and applied microbiology 14: 150-157.

[9] García-Valdés E, Mulet M, Lalucat J (2010) Insights into the life styles of Pseudomonas stutzeri Pseudomonas. Springer, pp. 177-198.

[10] Patwardhan A RS, Roy A (2014) Molecular Markers in Phylogenetic Studies - A Review. J Phylogen Evolution Biol 2. doi: 10.4172/2329-9002-2-131.

[11] B H (1986) Identification and distribution of Pseudomonas stutzeri in clinical material. J Appl Bacteriol 60: 401-411.

[12] Kalita M, Palusinska-Szysz M, Turska-Szewczuk A, Wdowiak-Wrobel S, Urbanik-Sypniewska T (2013) Isolation of cultivable microorganisms from Polish notes and coins. Pol J Microbiol 62: 281-286.

[13] Aradaib MEAaIE (2006) Association of Pseudomonas stutzeri with An Infected Ruptured Pulmonary Hydatid Cyst in A Young Patient. Surgery Journal 1: 32-34.

[14] Osman TMaES, S. M. (2013) Aerobic Bacteria Isolated from Dead in -Shell Chick Embryo in Khartoum State. The Sudan Journal of Veterinary Research 28: 1-7.

[15] E. Mohamed Ahmed HAAaIEA (2006) A Clinical Case of Recurrent Pleural Effusions, Culminating in Empyemathoraces in a Sudanese Woman with Yellow Nail Syndrome. International Journal of Tropical Medicine 1: 137-139.

[16] El-Hussein AA, Elsalahi RH, Osman AG, Sherif AM, El Siddig MA (2014) Isolation and 16S rRNA-Based Identification of Benomyl-Degrading Bacteria. British Biotechnology Journal 4: 670 .

[17] Lane DJ PB, Olsen GJ, Stahl DA, Sogin ML, Pace NR (1985) Rapid determination of 16S ribosomal RNA sequences for phylogenetic analyses. Proceedings of the National Academy of Sciences of the United States of America 82: 6955-6959.

[18] Cheesbrough M (2006) District laboratory practice in tropical countries- part 2 . Cambridge university press.
[19] Dart RK (1996) Microbiology for the analytical chemist. Royal Society of Chemistry.

[20] Giraffa G, Rossetti L, Neviani E (2000) An evaluation of chelex-based DNA purification protocols for the typing of lactic acid bacteria. Journal of Microbiological Methods 42: 175-184.

[21] Liu W, Bao Q, Qing M, Chen X, Sun T, Li M, Zhang J, Yu J, Bilige M, Sun T (2012) Isolation and identification of lactic acid bacteria from Tarag in Eastern Inner Mongolia of China by $16 \mathrm{~S}$ rRNA sequences and DGGE analysis. Microbiological research 167: 110-115.

[22] Lee PY, Costumbrado J, Hsu C-Y, Kim YH (2012) Agarose gel electrophoresis for the separation of DNA fragments. JoVE (Journal of Visualized Experiments): e3923-e3923.

[23] Finch TV software, (http://www.geospiza.com/ftvdlinfo.html).

[24] Altschul SF, Gish W, Miller W, Myers EW, Lipman DJ (1990) Basic local alignment search tool. Journal of molecular biology 215: 403-410.

[25] Benson DA, Cavanaugh M, Clark K, Karsch-Mizrachi I, Lipman DJ, Ostell J, Sayers EW (2013) GenBank. Nucleic acids research 41: D36-D42.

[26] Thompson JD, Higgins DG, Gibson TJ (1994) CLUSTAL W: improving the sensitivity of progressive multiple sequence alignment through sequence weighting, position-specific gap penalties and weight matrix choice. Nucleic acids research 22: 4673-4680.

[27] Okonechnikov K, Golosova O, Fursov M (2012) Unipro UGENE: a unified bioinformatics toolkit. Bioinformatics 28: 1166-1167.

[28] Maps of world (www.mapsofworld.com).

[29] Carlson CA, Pierson LS, Rosen J, Ingraham JL (1983) Pseudomonas stutzeri and related species undergo natural transformation. Journal of Bacteriology 153: 93-99.

[30] Sikorski J, Rosselló-Mora R, Lorenz MG (1999) Analysis of genotypic diversity and relationships among Pseudomonas stutzeri strains by PCR-based genomic fingerprinting and multilocus enzyme electrophoresis. Systematic and applied microbiology 22: 393-402.

[31] Scotta C, Gomila M, Mulet M, Lalucat J, García-Valdés E (2013) Whole-cell MALDI-TOF mass spectrometry and multilocus sequence analysis in the discrimination of Pseudomonas stutzeri populations: three novel genomovars. Microbial ecology 66: 522-532.

[32] Sikorski J, Teschner N, Wackernagel W (2002) Highly different levels of natural transformation are associated with genomic subgroups within a local population of Pseudomonas stutzeri from soil. Applied and environmental microbiology 68: 865-873.

[33] Alemu A (2014) Microbial contamination of currency notes and coins in circulation: a potential public health hazard. Biomedicine and Biotechnology 2: 46-53.

[34] Cladera AM, Bennasar A, Barceló M, Lalucat J, GarcíaValdés E (2004) Comparative genetic diversity of Pseudomonas stutzeri genomovars, clonal structure, and phylogeny of the species. Journal of bacteriology 186: 52395248 . 